\title{
Genetic variation in strigolactone production and tillering in rice and its effect on Striga hermonthica infection
}

\author{
Muhammad Jamil · Tatsiana Charnikhova • \\ Benyamin Houshyani - Aad van Ast • \\ Harro J. Bouwmeester
}

Received: 9 August 2011/Accepted: 5 September 2011/Published online: 25 September 2011

(C) The Author(s) 2011. This article is published with open access at Springerlink.com

\begin{abstract}
Tillering in cereals is a complex process in the regulation of which also signals from the roots in the form of strigolactones play an important role. The strigolactones are signalling molecules that are secreted into the rhizosphere where they act as germination stimulants for root parasitic plants and hyphal branching factors for arbuscular mycorrhizal fungi. On the other hand, they are also transported from the roots to the shoot where they inhibit tillering or branching. In the present study, the genetic variation in strigolactone production and tillering phenotype was studied in twenty rice varieties collected from all over the world and correlated with S. hermonthica infection. Rice cultivars like IAC 165, IAC 1246, Gangweondo and Kinko produced high amounts of the strigolactones orobanchol, 2'-epi-5-deoxystrigol and three methoxy-5deoxystrigol isomers and displayed low amounts of tillers. These varieties induced high $S$. hermonthica germination,
\end{abstract}

Electronic supplementary material The online version of this article (doi:10.1007/s00425-011-1520-y) contains supplementary material, which is available to authorized users.

M. Jamil · T. Charnikhova $\cdot$ B. Houshyani

Laboratory of Plant Physiology, Wageningen University,

Wageningen, The Netherlands

A. van Ast

Centre for Crop Systems Analysis (CCSA), Crop and Weed

Ecology Group, Wageningen University, Wageningen,

The Netherlands

H. J. Bouwmeester $(\square)$

Laboratory of Plant Physiology, Wageningen University, Droevendaalsesteeg 1, 6708 PB Wageningen, The Netherlands e-mail: harro.bouwmeester@wur.nl

H. J. Bouwmeester

Centre for Biosystems Genomics, Wageningen, The Netherlands attachment, emergence as well as dry biomass. In contrast, rice cultivars such as Super Basmati, TN 1, Anakila and Agee displayed high tillering in combination with low production of the aforementioned strigolactones. These varieties induced only low $S$. hermonthica germination, attachment, emergence and dry biomass. Statistical analysis across all the varieties confirmed a positive correlation between strigolactone production and $S$. hermonthica infection and a negative relationship with tillering. These results show that genetic variation in tillering capacity is the result of genetic variation in strigolactone production and hence could be a helpful tool in selecting rice cultivars that are less susceptible to $S$. hermonthica infection.

Keywords Rice $\cdot$ Strigolactones $\cdot$ Striga $\cdot$ Tillering

$\begin{array}{ll}\text { Abbreviations } \\ \text { UPLC } & \text { Ultra performance liquid chromatography } \\ \text { MS } & \text { Mass spectrometry } \\ \text { MRM } & \text { Multiple reaction monitoring } \\ \text { AM } & \text { Arbuscular mycorrhizal } \\ \text { M } & \text { Molar } \\ \text { MCP } & \text { Monte Carlo permutation }\end{array}$

\section{Introduction}

A tiller is a specialized grain-bearing stem that sprouts from the base of plant species in the Poaceae. Tillering is one of the most important agronomic traits in poaceous crops and plays a major role in determining plant architecture and grain yield ( $\mathrm{Wu}$ et al. 1998). Tillering (and branching in dicotyledonous crops) is a complex process that involves the fine-tuned, coordinated expression of 
many genes (Ongaro and Leyser 2007) and is regulated by the interaction of genetic, hormonal and environmental cues (Ward and Leyser 2004; Garba et al. 2007; Kim et al. 2010a, b). Initially, two classes of hormones-auxins and cytokinins-have long been assumed to control tillering and shoot branching (Leyser 2003; Hayward et al. 2009). But recently a novel class of plant hormones, the strigolactones, was identified to also be involved in the regulation of above-ground plant architecture by inhibiting tiller production/shoot branching (Gomez-Roldan et al. 2008; Crawford et al. 2010; Umehara et al. 2010). The production of strigolactones is particularly strongly up-regulated under low-phosphate conditions (Yoenyama et al. 2007; Jamil et al. 2011a). Under phosphorus deficiency, the modification in plant architecture by strigolactones (reduced tillering/shoot branching) is proposed to be an adoptive strategy to these growth-limiting conditions (Umehara et al. 2010; Kohlen et al. 2011a). In addition, there is increasing evidence that under phosphorus limitation, strigolactones also play a role in the adaptation of root architecture to better cope with this nutrient limitation (Koltai et al. 2010; Kapulnik et al. 2011; Ruyter-Spira et al. 2011). Another adaptation to improve uptake of mineral nutrients in which strigolactones play a key role-but now not as plant hormone but as rhizosphere signalling molecule-is the stimulation of the symbiotic interaction with arbuscular mycorrhizal (AM) fungi (Akiyama et al. 2005). The strigolactones act as a hyphal branching factor for AM fungi and hence stimulate the development of a symbiotic relation (Akiyama et al. 2005). The AM fungi play an important role in providing mineral nutrients, especially phosphorus, to more than $80 \%$ of land plant species (Harrison 2005; Akiyama and Hayashi 2006; Bouwmeester et al. 2007).

However, the strigolactones have a second rhizosphere signalling role. They also act as germination stimulants for seeds of root parasitic plants of the Striga, Orobanche and Phelipanche genera, resulting in a parasitic interaction between host and parasite (Bouwmeester et al. 2003; Xie et al. 2010). The seeds of these parasitic plants will only germinate after perceiving the germination stimulant from their host (Bouwmeester et al. 2003; Yoneyama et al. 2010). After germination, the parasite attaches and penetrates the host root by a specialized feeding structure, the haustorium (Lynn and Chang 1990; Estabrook and Yoder 1998; Yoder 2001). The parasitic plant grows underground for 4 to 7 weeks prior to emergence and utilizes host water, nutrients and photosynthate. Much of the damage to the host occurs already at this stage. About $20-80 \%$ yield losses or even complete crop failure can occur due to this parasitism.

The triple role of strigolactones in underground communication between host plants, AM fungi and parasitic plants, and the regulation of tillering/branching raises a number of questions. One of these is if the tillering/ branching phenotype is indicative of the production of strigolactones and their secretion into the rhizosphere and whether then the tillering phenotype is also an indication of the plant's susceptibility to root parasitic plant infection. If this is the case, screening of cultivars for their tillering/ branching phenotype could be an easy tool for breeders to select lines with better parasitic plant resistance. In the present study we applied this question to rice with the aims to correlate rice tillering with strigolactone production and to link this feature with $S$. hermonthica infection in a range of rice cultivars from all over the world.

\section{Materials and methods}

\section{Plant material}

In a first study, about 50 rice cultivars collected from different areas of the world were studied for strigolactone production and tillering capacity. Out of these 50 rice cultivars, 20 rice cultivars were selected for further experiments based on the variation in strigolactone production, tillering and $S$. hermonthica germination, attachment and emergence. The details of the selected 20 rice cultivars are given in Table 1. The rice cultivars represent different origins of the world, especially Africa and Asia and represent Oryza japonica, Oryza indica and Oryza javanica backgrounds. All the experiments were conducted in a completely randomized design with three replicates under controlled greenhouse conditions $\left(28^{\circ} \mathrm{C} / 25^{\circ} \mathrm{C}\right.$ with $10 \mathrm{~h}$ (day)/14 h (night) photoperiod and $70 \%$ relative humidity) or in a climate chamber $\left(28^{\circ} \mathrm{C} / 25^{\circ} \mathrm{C}\right.$ with $10 \mathrm{~h}$ (day)/14 h (night) photoperiod $\left(450 \mu \mathrm{M} \mathrm{m}^{-2} \mathrm{~s}^{-1}\right)$ and $70 \%$ relative humidity) in Wageningen, The Netherlands.

\section{Strigolactone analysis}

Strigolactones were analysed in root exudates as well as in root extracts. The seeds of all cultivars were surface sterilized with $2 \%$ sodium hypochlorite and placed to germinate in an incubator at $30^{\circ} \mathrm{C}$ for $48 \mathrm{~h}$. About $1.5 \mathrm{~L}$ silver sand was added to a $3.0 \mathrm{~L}$ plastic pot and 15 pre-germinated seeds of each cultivar, in three replicates, were planted in an individual pot and grown in the climate chamber. During the 2nd week, thinning was done to ten plants in each pot. Each pot was supplied with $250 \mathrm{~mL}$ half-strength modified Hoagland's nutrient solution with $100 \%$ phosphorus (P; $0.4 \mathrm{mM}$ ) for 4 weeks (at $48 \mathrm{~h}$ interval). In week $5,3 \mathrm{~L}$ phosphorus deficient nutrient solution was added on top of the sand and allowed to drain from each pot. The phosphorus deficiency was maintained for 1 week, after which another $3 \mathrm{~L}$ phosphorus-deficient 
Table 1 List of rice cultivars screened for tillering, strigolactones production and Striga hermonthica infection

\begin{tabular}{|c|c|c|c|c|c|c|c|c|}
\hline $\begin{array}{l}\text { S. } \\
\text { No. }\end{array}$ & $\begin{array}{l}\text { Variety } \\
\text { name }\end{array}$ & Rice species & Group & Seed source & $\begin{array}{l}\text { Country } \\
\text { of origin }\end{array}$ & Tall/dwarf & $\begin{array}{l}\text { Tillering } \\
(\text { No. } \\
\left.\text { plant }^{-1}\right)\end{array}$ & $\begin{array}{l}\text { Upland/ } \\
\text { lowland }\end{array}$ \\
\hline 1 & IAC 165 & Oryza sativa & Japonica & $\begin{array}{l}\text { University of } \\
\text { Sheffield }\end{array}$ & Brazil & Tall & 6 & Upland \\
\hline 2 & IAC 1246 & Oryza sativa & Japonica & IRRI Philippines & Brazil & Tall & 6 & upland \\
\hline 3 & Gangweondo & Oryza sativa & Japonica & IRRI Philippines & $\begin{array}{l}\text { South } \\
\text { Korea }\end{array}$ & Tall & 7 & $\begin{array}{l}\text { No } \\
\text { information }\end{array}$ \\
\hline 4 & Kinko & Oryza sativa & Indica & IRRI Philippines & Guinea & Tall & 7 & $\begin{array}{l}\text { No } \\
\text { information }\end{array}$ \\
\hline 5 & Dullo & Oryza sativa & Indica & IRRI Philippines & India & Tall & 8 & $\begin{array}{l}\text { No } \\
\text { information }\end{array}$ \\
\hline 6 & Binagimbing & Oryza sativa & Indica & IRRI Philippines & Philippines & Intermediate & 8 & Upland \\
\hline 7 & Sonkanoir & Oryza sativa & Indica & IRRI Philippines & Liberia & Intermediate & 8 & $\begin{array}{l}\text { No } \\
\text { information }\end{array}$ \\
\hline 8 & $20 \mathrm{D}$ & Oryza sativa & Indica & IRRI Philippines & Liberia & Intermediate & 9 & Upland \\
\hline 9 & TOS 7556 & Oryza sativa & $\begin{array}{l}\text { Javanica (Tropical } \\
\text { japonica) }\end{array}$ & IRRI Philippines & $\begin{array}{l}\text { Ivory } \\
\text { Coast }\end{array}$ & Intermediate & 8 & Upland \\
\hline 10 & Kairyo-HM & Oryza sativa & Japonica & IRRI Philippines & Japan & Intermediate & 9 & $\begin{array}{l}\text { No } \\
\text { information }\end{array}$ \\
\hline 11 & PI 160641 & Oryza sativa & Indica & IRRI Philippines & China & Intermediate & 11 & $\begin{array}{l}\text { No } \\
\text { information }\end{array}$ \\
\hline 12 & Koirao Baleo & $\begin{array}{l}\text { Oryza } \\
\quad \text { glaberrima }\end{array}$ & $-^{\mathrm{a}}$ & IRRI Philippines & Mali & Intermediate & 11 & Upland \\
\hline 13 & Bhasmanik & Oryza sativa & Indica & IRRI Philippines & India & Intermediate & 12 & $\begin{array}{l}\text { No } \\
\text { information }\end{array}$ \\
\hline 14 & $\begin{array}{l}\text { Shuang- } \\
\text { Chiang }\end{array}$ & Oryza sativa & Indica & IRRI Philippines & Taiwan & Intermediate & 12 & $\begin{array}{l}\text { No } \\
\text { information }\end{array}$ \\
\hline 15 & Peh-Kuh & Oryza sativa & Indica & IRRI Philippines & Taiwan & Dwarf & 13 & $\begin{array}{l}\text { No } \\
\text { information }\end{array}$ \\
\hline 16 & Tattare & $\begin{array}{l}\text { Oryza } \\
\text { glaberrima }\end{array}$ & $-{ }^{\mathrm{a}}$ & IRRI Philippines & Nigeria & Dwarf & 12 & $\begin{array}{l}\text { No } \\
\text { information }\end{array}$ \\
\hline 17 & Agee & $\begin{array}{l}\text { Oryza } \\
\quad \text { glaberrima }\end{array}$ & $-^{\mathrm{a}}$ & IRRI Philippines & Ghana & Dwarf & 12 & $\begin{array}{l}\text { No } \\
\text { information }\end{array}$ \\
\hline 18 & Anakila & $\begin{array}{l}\text { Oryza } \\
\quad \text { glaberrima }\end{array}$ & $-{ }^{\mathrm{a}}$ & IRRI Philippines & Mali & Dwarf & 14 & $\begin{array}{l}\text { No } \\
\text { information }\end{array}$ \\
\hline 19 & TN 1 & Oryza sativa & Indica & IRRI Philippines & Taiwan & Dwarf & 16 & Intermediate \\
\hline 20 & $\begin{array}{l}\text { Super } \\
\text { Basmati }\end{array}$ & Oryza sativa & Indica & NARC, Pakistan & Pakistan & Dwarf & 18 & Lowland \\
\hline
\end{tabular}

${ }^{a}$ Japonica/Indica/Javanica are different eco-geographic groupings of Oryza sativa only, not applied to Oryza glaberrima

nutrient solution was applied and drained away freely to remove accumulated strigolactones from the rhizosphere. After $48 \mathrm{~h}$, root exudates were collected from the rhizosphere of each pot by adding and draining $1.5 \mathrm{~L}$ phosphorus-deficient nutrient solution through each pot. The collected solutions were passed through SPE C18-Fast columns $(500 \mathrm{mg} / 3 \mathrm{~mL})$ and the strigolactones eluted with $6 \mathrm{~mL} \mathrm{100 \%}$ acetone. Various strigolactones such as orobanchol, 2'-epi-5-deoxystrigol and three methoxy-5-deoxystrigol isomers (Fig. 1) were identified and quantified using ultra performance liquid chromatography tandem mass spectrometry (UPLC-MS/MS) (Waters, Milford MA USA) as described previously (Jamil et al. 2011a).

Strigolactones were also measured in root extracts of the first four highest strigolactone producing and last four lowest producing rice cultivars. Hereto, root tissues from these cultivars were frozen with liquid nitrogen and ground into powder. About $500 \mathrm{mg}$ of ground powder of each sample was taken in a pre-cooled glass vial. Then $4 \mathrm{~mL}$ ethyl acetate and $0.02 \mathrm{nmol}$ of $\mathrm{D}_{6}-2^{\prime}$-epi-5-deoxystrigol (provided by T. Asami, Department of Applied Biological Chemistry, The University of Tokyo, Japan) as internal 
Fig. 1 Chemical structure of orobanchol (a), 2'-epi-5deoxystrigol (b) and methoxy5-deoxystrigol isomers 1-3 (position and stereochemistry unknown) (c) in the root exudates and root extracts of rice cultivars. (Adapted from Jamil et al. 2011b) (a)

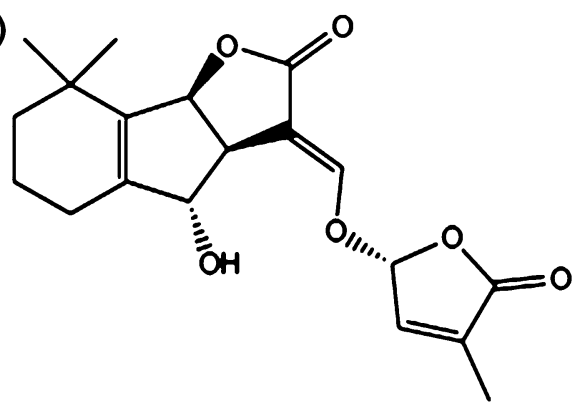

orobanchol

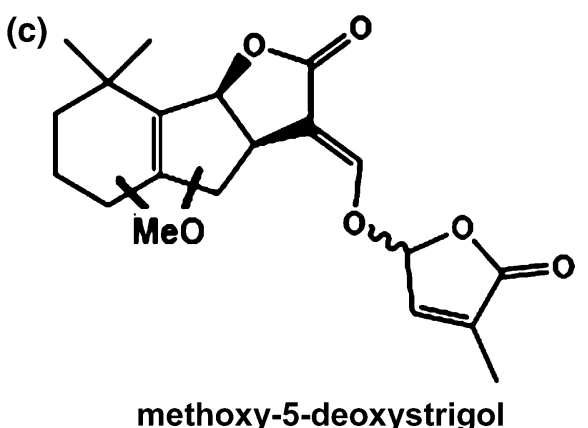

methoxy-5-deoxystrigol

(c) (b)

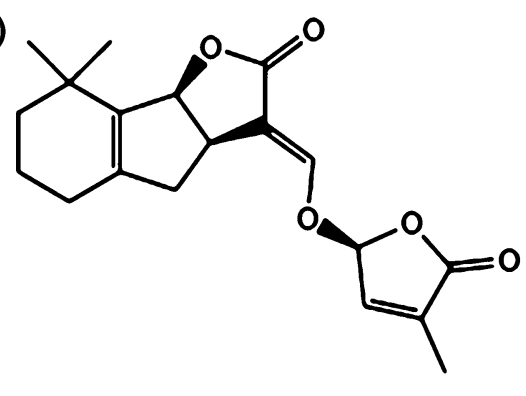

2'-epi-5-deoxystrigol standard were added and the samples sonicated for $10 \mathrm{~min}$. After sonification and vortexing, the samples were centrifuged at 2,000 g for $10 \mathrm{~min}$. The supernatant was collected carefully and added to a new glass vial. The strigolactones collected in this way were identified and quantified through ultra performance liquid chromatography coupled to tandem mass spectrometry (UPLC-MS/MS) using multiple reaction monitoring (MRM) as described by Jamil et al. (2011a). The retention times and mass transitions of strigolactone standards orobanchol and 2'-epi-5-deoxystrigol (provided by Koichi Yoneyama, Weed Science Center, Utsunomiya University, Japan) and 5-deoxystrigol (provided by Kohki Akiyama, Osaka Prefecture University, Japan) were used to identify rice strigolactones. Strigolactones putatively identified as methoxy-5-deoxystrigol isomers 1-3 (Jamil et al. 2011b; C. Cardoso, WUR, personal communication) were also identified by using MRM transitions (channels) $\mathrm{m} / z 361>247$ and $361>97$.

Tillering diversity among rice cultivars

To determine the tillering diversity, the seeds of each rice cultivar were surface sterilized with $0.2 \%$ sodium hypochlorite and put to germinate in separate sealed Petri dish in an incubator at $30^{\circ} \mathrm{C}$ for $48 \mathrm{~h}$. One pregerminated seed of each rice cultivar was planted in the centre of a 1-L plastic pot, filled with $800 \mathrm{~mL}$ silver sand. The rice seedlings in this completely randomized design experiment with three replicates were allowed to grow under green house-controlled conditions as mentioned above. Half strength Hoagland's nutrients solution was applied $(250 \mathrm{~mL}$ at $48 \mathrm{~h}$ interval) with $100 \%$ phosphorus $(0.4 \mathrm{mM})$ and then after 1 week the dose of $\mathrm{P}$ reduced to $20 \%(0.08 \mathrm{mM})$ to induce strigolactone production. To determine number of tillers per plant, the plants were grown for about 8 weeks (58 days). The tillers per plant of each cultivar were counted manually from each pot.

\section{Striga hermonthica germination bioassays}

Root exudates obtained from different rice cultivars were assessed for germination stimulatory activity by germination bioassays with seeds of Striga hermonthica. Surfacesterilization of $S$. hermonthica seeds was done using $25 \mathrm{~mL}$ of $2 \%$ sodium hypochlorite with $0.4 \%$ of Tween-20 for $5 \mathrm{~min}$. Subsequently, seeds were thoroughly rinsed three times with 10-min intervals, using sterile demineralized water, through a Buchner funnel. The sterile seeds were air dried for $60 \mathrm{~min}$. Approximately 50-100 seeds were then evenly spread on 9-mm diameter glass fibre filter paper discs (Sartorius, Goettingen Germany). These discs were placed in 9-cm diameter Petri-dishes (12 discs per Petridish) on filter paper (Whatman, Maidstone, UK) moistened with $3 \mathrm{~mL}$ demineralized water. For preconditioning, the Petri-dishes were sealed with parafilm, wrapped in aluminium foil and placed in an incubator in darkness at $30^{\circ} \mathrm{C}$ for 10 days.

After 10 days, the discs with preconditioned seeds were allowed to dry for $50 \mathrm{~min}$ in a laminar flow cabinet to 
evaporate surplus moisture. The discs were then placed in another Petri-dish (six per Petri-dish) containing a filter paper ring (outer diameter $9 \mathrm{~cm}$, inner diameter $8 \mathrm{~cm}$ ) moistened with $0.9 \mathrm{~mL}$ water. The samples to be tested were applied $(50 \mu \mathrm{L}$ per disc) in three replicates after replacement of the acetone in the samples by water through vacuum centrifugation. GR24 $(3.3 \mu \mathrm{M})$ was used as a positive control and water as a negative control in each germination assays. Seeds were again incubated at $30^{\circ} \mathrm{C}$ in darkness for $48 \mathrm{~h}$ and germination (seeds with radicle protruding through the seed coat) was scored using a binocular microscope (Matusova et al. 2005).

\section{Striga hermonthica attachment}

The response of high and low tillering cultivars for S. hermonthica attachment was assessed in a pot study. All rice cultivars were grown in a completely randomized design with three replicates. A perforated plastic sheet was put in the bottom of $1.5 \mathrm{~L}$ plastic pot. After addition of $100 \mathrm{~mL}$. hermonthica free silver sand on the bottom of the pot, a mixture of $500 \mathrm{~mL}$ sand with $25 \mathrm{mg}$ of $S$. hermonthica seeds was placed on top of the Striga-free layer. One pre-germinated, seed of each rice cultivar was planted in the centre of each pot and covered by another $100 \mathrm{~mL}$ of $S$. hermonthica free sand. During the first week, half-strength modified Hoagland's nutrient solution with $100 \% \mathrm{P}$ was applied $(250 \mathrm{~mL}$ at $48 \mathrm{~h}$ interval). Subsequently, the phosphorus dose was reduced to $20 \%$ and $250 \mathrm{~mL}$ of this nutrient solution was applied at 48-h intervals. The plants were grown for 8 weeks under greenhouse conditions as mentioned above. After 8 weeks, sand was removed carefully by washing the root systems of the rice plants and S. hermonthica attachment counted under a binocular.

\section{Striga hermonthica emergence}

S. hermonthica emergence and dry biomass production were assessed in a separate experiment. A mixture of soil (Lentse Potgrond, Katwijk, The Netherland) and silver sand in a ratio of 1:1 (w/w) was prepared. About $200 \mathrm{~mL}$ of this medium without Striga seed was added in the bottom of a $1.5 \mathrm{~L}$ plastic pot and then $500 \mathrm{~mL}$ of this medium, mixed with $25 \mathrm{mg} S$. hermonthica seeds was added. Finally, $100 \mathrm{~mL}$ of above-mentioned medium without Striga seed was added on top. A pre-germinated seed of each cultivar was planted in the centre of each pot. The plants were grown under the greenhouse conditions described above for 12 weeks. After counting $S$. hermonthica emergence the Striga plants were up-rooted, oven dried at $70^{\circ} \mathrm{C}$ for $72 \mathrm{~h}$ and then weighed.
Statistical analysis

The data on S. hermonthica germination, attachment, emergence and dry biomass were analysed statistically by ANOVA in conjunction with LSD Posthoc test using Genstat 9.2 (VSN Int. Ltd., Hemel, Hempstead, UK). The relationship between various strigolactones and $S$. hermonthica germination and tillering was analysed by correlation analysis using $\mathrm{R}$. For a multivariate approach, the average strigolactone peak areas of the rice cultivars were symmetrically scaled by the standard deviation (SD) of the samples and the individual strigolactones. The SD-scaled data were used (without log transformation) in redundancy analysis (RDA), to examine whether the variation in the strigolactones explains the variation in average infection parameters of the rice genotypes. We used a forward selection approach to identify the strigolactones with the highest explanatory power. A Monte Carlo permutation (MCP) test was used to assess the statistical significance of the ordination axes of the canonical analysis and of the environmental variables. All the multivariate data analysis was performed in CANOCO 4.5 for windows (ter Braak 1988).

\section{Results}

\section{Tillering}

The rice cultivars differed strongly with regard to their tillering phenotype (Fig. 2). The average number of tillers varied from 6 to 18 tillers per plant (Fig. 3; Suppl. Table S1). The rice cultivars Super Basmati, TN 1, Agee, and Anakila showed the highest tillering (13-18 tillers per plant) while rice cultivars such as IAC 165, IAC 1246, Gangweondo and Kinko displayed much lower number of tillers per plant (Figs. 2, 3). The rest of the cultivars were in the range of 8-12 tillers per plant (Suppl. Table S1).

\section{Striga hermonthica infection}

The exudates of low tillering rice cultivars IAC 165, IAC 1246, Gangweondo, and Kinko induced the highest $S$. hermonthica germination rate $(\geq 50 \%)$, while high-tillering rice cultivars like Super Basmati, TN 1, Anakila and Agee induced significantly less germination of $S$. hermonthica. Bhasmanik, Shuang, Pehkuh, Tattare were the other four cultivars inducing less than $25 \%$ germination (Fig. 3; Suppl. Table S1). The four lowest tillering rice cultivars with high in vitro germination rates (IAC 165, IAC 1246, Gangweondo and Kinko) also had the highest S. hermonthica attachment. In contrast, the high-tillering rice cultivars, with the lowest germination rates (Super 
Fig. 2 Differences in tillering in some representative low and high-tillering rice cultivars. The average number of tillers (between brackets) at 8 weeks after sowing were: IAC 165 (6), IAC 1246 (6), Gangweondo (7), Kinko (7), Agee (12), Anakila (14), TN 1 (16) and Super Basmati (18)

Fig. 3 Numbers of tillers, Striga hermonthica germination (\%) induced by root exudate, attachment (No.), emergence (No.) and dry biomass (g) of $S$. hermonthica in a series of rice cultivars. Bars represent mean $\pm \mathrm{SE}(n=3)$. The line represents average number of tillers per plant $\pm \operatorname{SE}(n=3)$

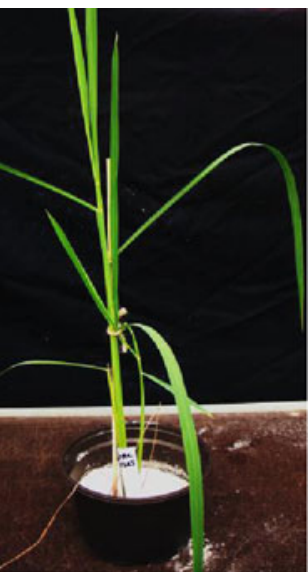

IAC 165

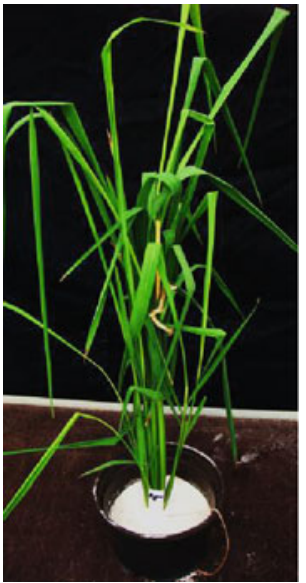

Agee

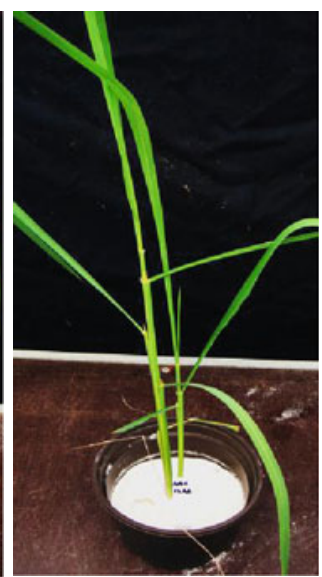

IAC 1246

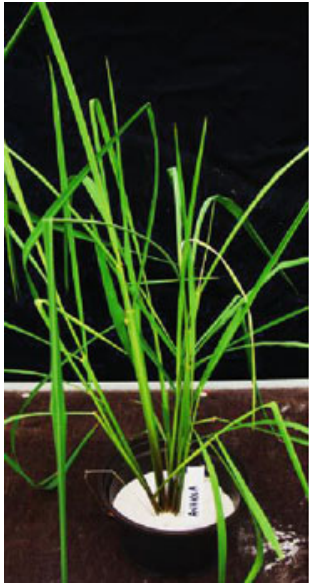

Anakila

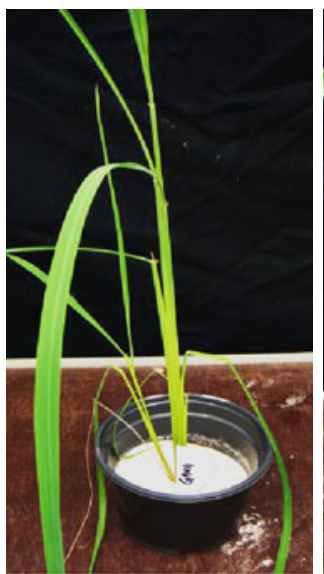

Gangweondo

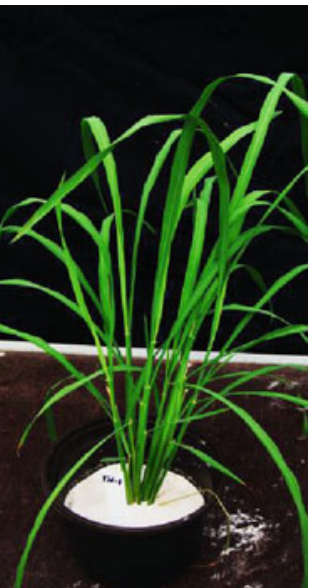

TN 1

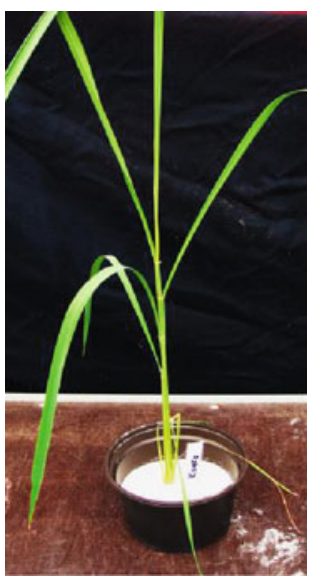

Kinko

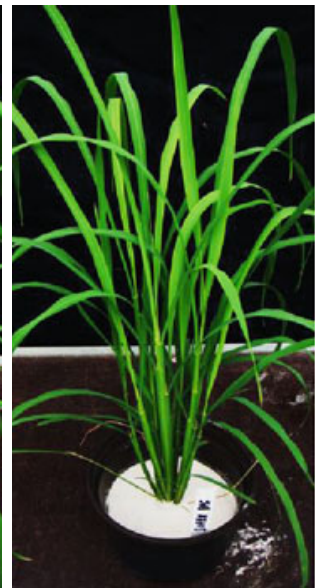

Super Basmati

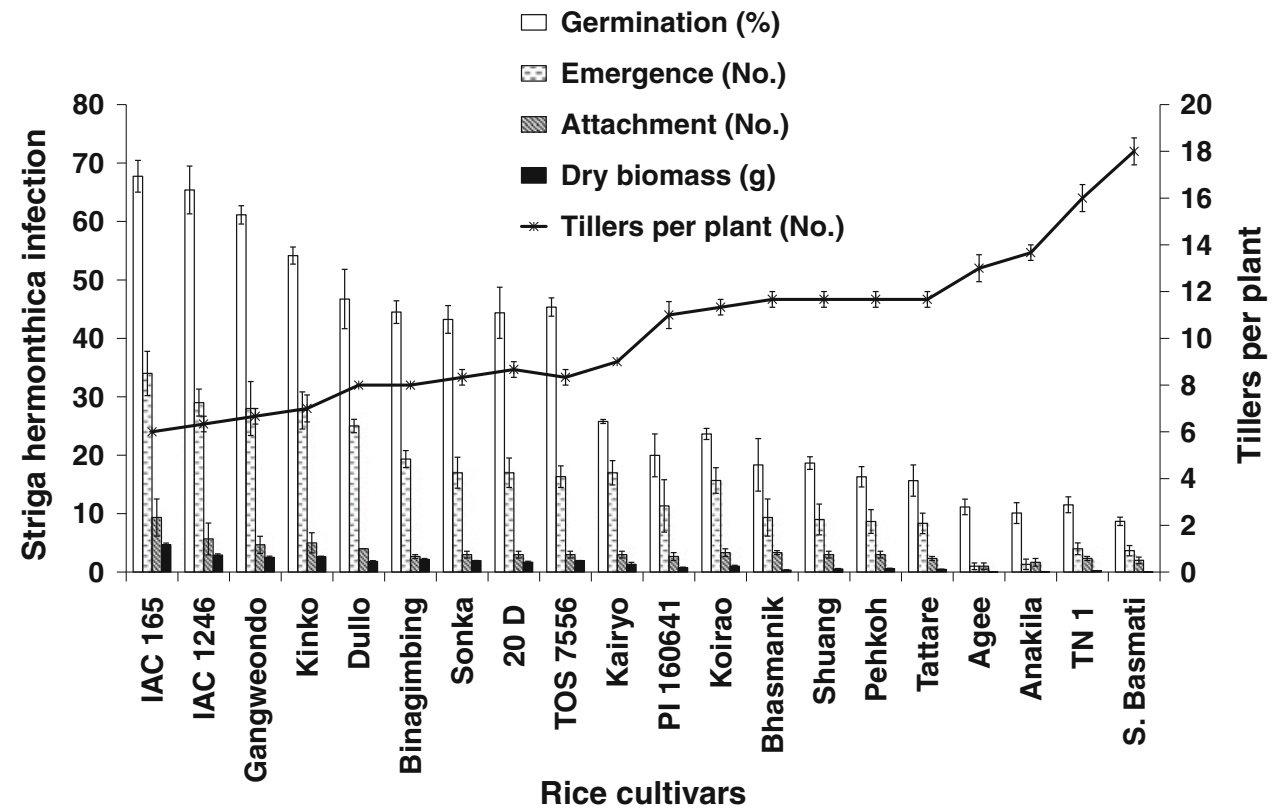


Basmati, TN 1, Anakila and Agee), had the lowest number of S. hermonthica attachments (Fig. 3). For most of the other cultivars, $S$. hermonthica attachment was similar to their position based on germination rate (Suppl. Table S1).

In line with the germination and attachments results, the four low tillering rice cultivars also displayed the highest $S$. hermonthica emergence ( $>25$ plants per pot) while hightillering cultivars as Agee, Anakila, TN 1 and Super Basmati showed significantly $(P<0.01)$ lower $S$. hermonthica emergence numbers ( $<4$ plants per pot) (Figs. 3,4$)$. The rest of the rice cultivars showed intermediate $S$. hermonthica emergence (8-25 plants per pot) (Suppl. Table $\mathrm{S} 1)$. In accordance with the high $S$. hermonthica emergence, the low tillering rice cultivars, IAC 165, IAC 1246, Gangweondo and Kinko supported the highest $S$. hermonthica biomass (Fig. 3), while the lowest S. hermonthica biomass was found on the high-tillering rice cultivars Super Basmati, TN 1, Anakila and Agee. The latter varieties supported significantly $(P<0.01)$ lower $S$. hermonthica biomass than $80 \%$ of the other cultivars. The other moderate tillering rice cultivars, like Tattare, Pehkuh, Shuang, Bhasmanik, Koirao and PI 160641 showed significantly lower $S$. hermonthica dry biomass (<600 mg) than $50 \%$ of the other cultivars (Suppl. Table S1).

\section{Strigolactone production}

The concentration of strigolactones in the exudate varied strongly between the rice cultivars (Fig. 5a; Suppl. Table $\mathrm{S} 2$ ). The low tillering cultivars IAC 165, IAC 1246, Gangweondo, and Kinko were found to be top four highest strigolactone producers (Fig. 5a). The cultivars Dullo, Binagimbing, Sonka, 20D, TOS 7556, Kairyo, Tattare, Shuang, Pehkoh and Bhashmanik showed intermediate production levels, while the high-tillering cultivars Super Basmati, TN 1, Anakila and Agee were found as lowest strigolactone producers (Fig. 5a; Suppl. Table S2). Also the endogenous concentration of strigolactones in roots was high in the low tillering cultivars IAC 165, IAC 1246, Gangweondo and Kinko and low in the high-tillering cultivars Super Basmati, TN 1, Anakila and Agee (Fig. 5b). In addition to differences in the total amount of strigolactones, the cultivars also showed differences in the composition of strigolactones (Fig. 5a, b). The four cultivars
Fig. 4 Striga hermonthica emergence in some representative low- and hightillering rice cultivars as determined 12 weeks after sowing. The average number of $S$. hermonthica shoots emerged (between brackets) were: IAC 165 (34), IAC 1246 (29), Gangweondo (28), Kinko (28), Agee (1), Anakila (1), TN 1 (4) and Super Basmati (4)

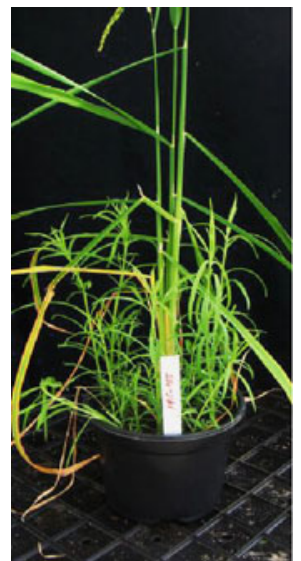

IAC 165

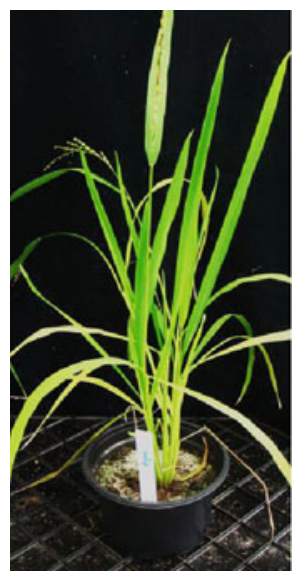

Agee

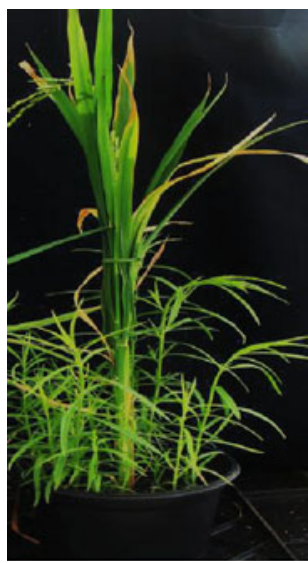

IAC 1246

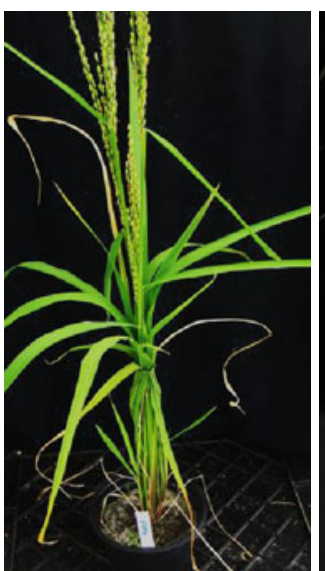

Anakila

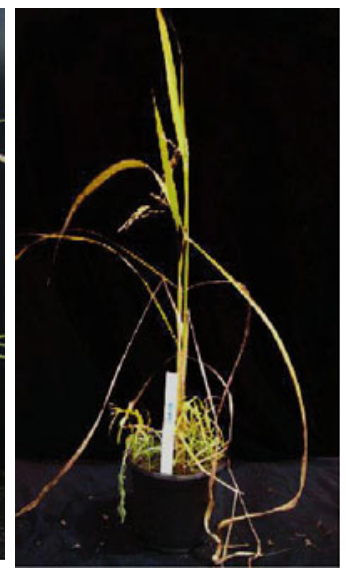

Gangweondo

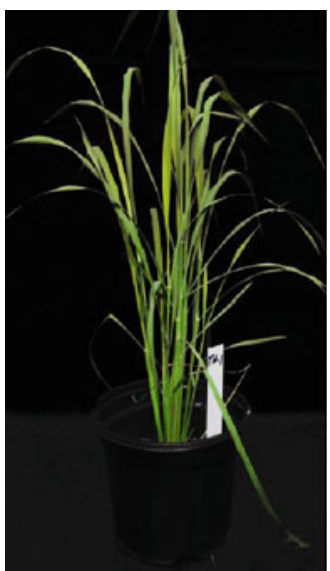

TN 1

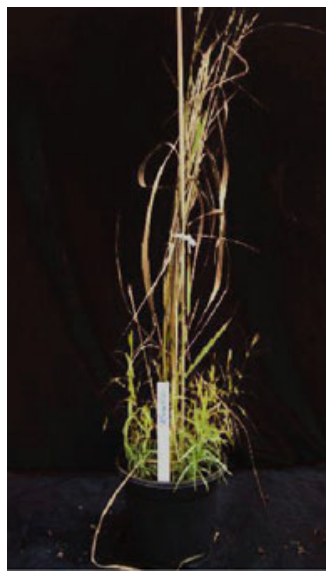

Kinko

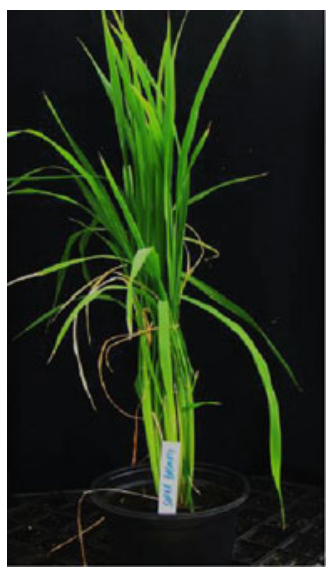

Super Basmati 
Fig. 5 Strigolactone concentration in the root exudates (a) and root tissues (b) of rice cultivars: $2^{\prime}$-epi-5deoxystrigol (filled square), orobanchol (open square) and methoxy-5-deoxystrigol isomers 1-3 (horizontal box, diagonal box, dotted box). Bars represent means of peak areas of the individual strigolactones as determined by multiple reaction monitoring liquid chromatography-mass spectrometry in triplicate. The line represents the average number of tillers per plant $\pm \mathrm{SE}$ $(n=3)$ (a)

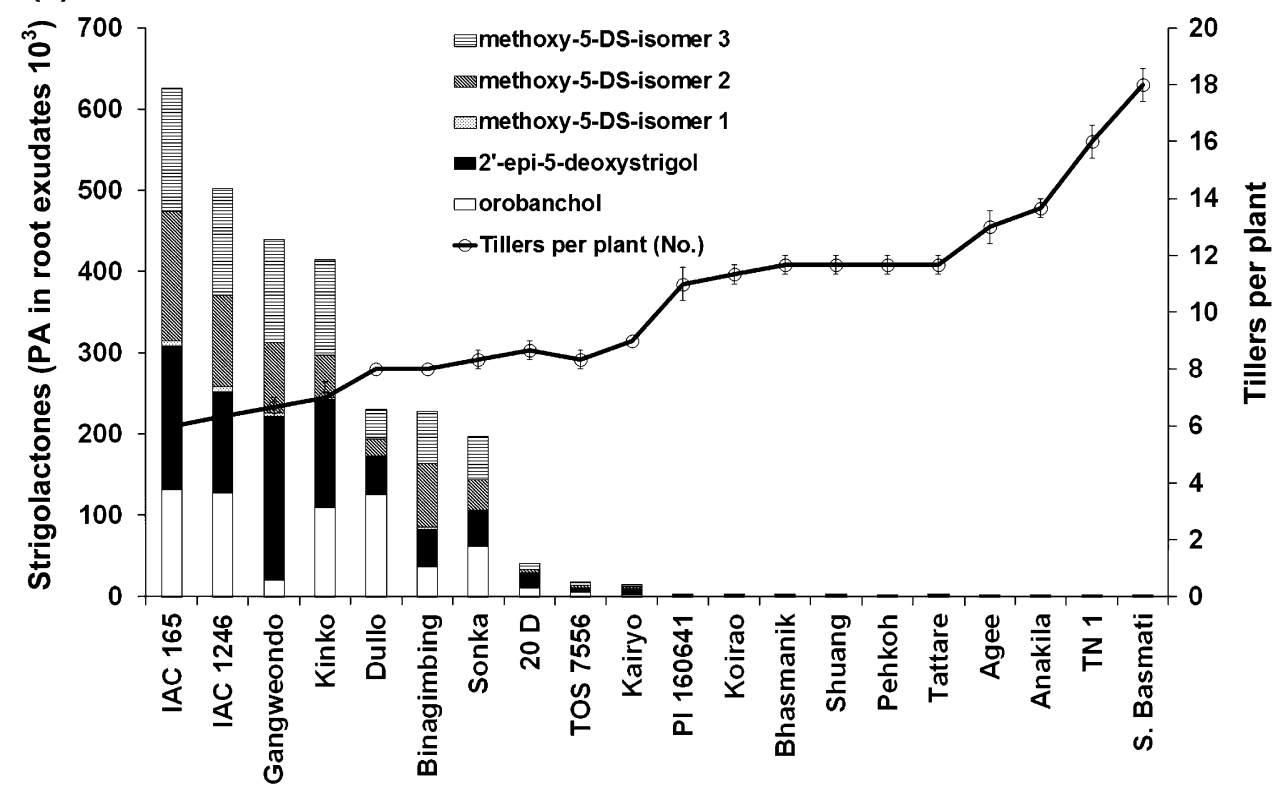

(b)

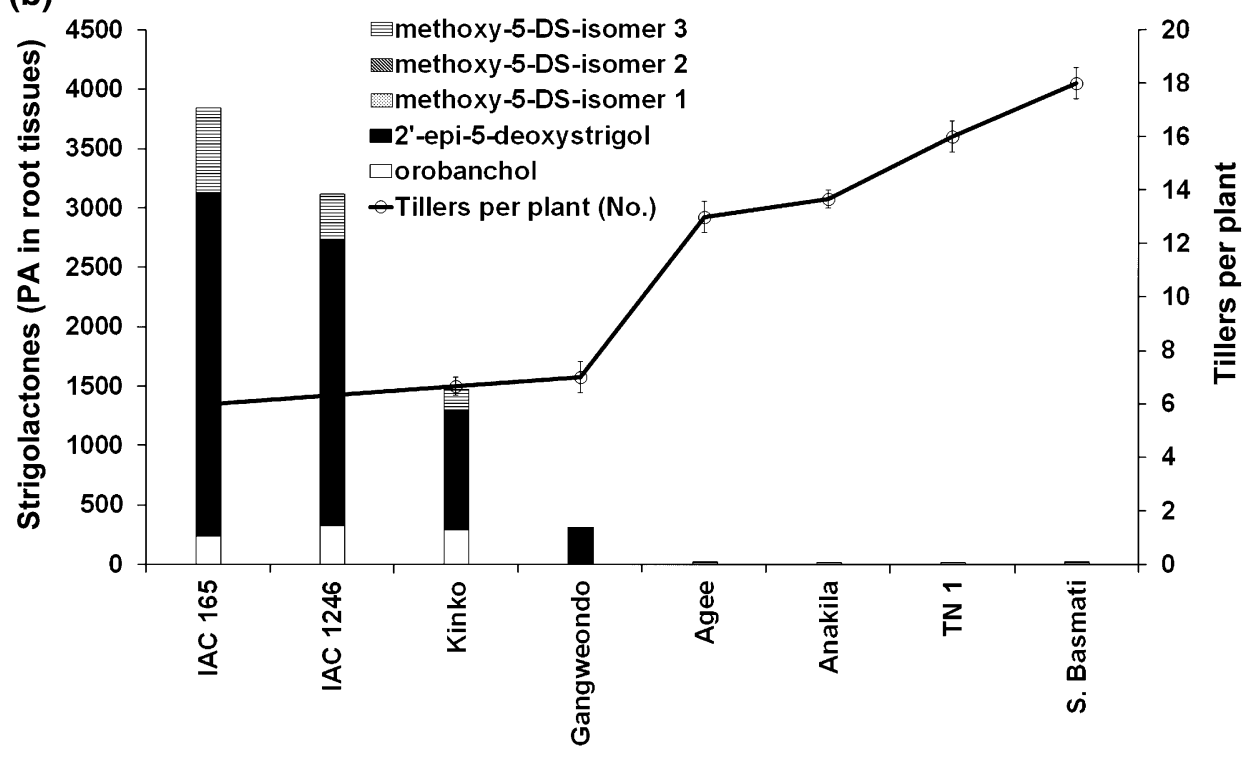

Rice cultivars producing the highest amount of 2'-epi-5-deoxystrigol included Gangweondo, IAC 165, Kinko and IAC 1246 (Fig. 5a, b; Suppl. Tables S2 and S3). For orobanchol, the highest producing cultivars were IAC 165, IAC 1246, Dullo and Kinko (Fig. 5a). The cultivars IAC 165, IAC 1246, Gangweondo and Kinko produced high levels of at least two of the three methoxy-5-deoxystrigol isomers 1-3 (Fig. 5a, b). The rice cultivar IAC 165 ranked on top for the amount of orobanchol and methoxy-5-deoxystrigol isomers 1-3 in the root exudate but in the root itself contained the highest amount of $2^{\prime}$-epi-5-deoxystrigol (Fig. 5a, b).
Relationship between tillering, strigolactone production and $S$. hermonthica infection

The above data show that there is an inverse relationship between the number of tillers per plant and S. hermonthica parasitism parameters (germination, attachment, emergence, dry biomass) as well as strigolactone production (Figs. 3, 5a, b). Regression analysis (on the basis of peak area) revealed that methoxy-5-deoxystrigol isomer 3 contributes most to the explanation of the variation in $S$. hermonthica germination and emergence in these rice cultivars followed by 2'-epi-5-deoxstrigol (Suppl. Table S4). The 
strigolactones did not contribute significantly to the explanation of variation in $S$. hermonthica attachment (Suppl. Table S4). 2'-Epi-5-deoxystrigol also contributes significantly to the explanation of variation in tiller numbers in contrast to the other strigolactones. However, correlation analysis showed that 2'-epi-5-deoxystrigol, orobanchol and the methoxy-5-deoxystrigol isomers 1-3 also closely correlate with each other (and S. hermonthica germination, attachment and emergence) (Suppl. Table S6). Interestingly, there was a higher correlation between 2 -epi-5-deoxystrigol and the three methoxy-isomers (0.77-0.81) than between orobanchol and these three isomers (0.60-0.66). The correlation between orobanchol and 2 -epi-5-deoxystrigol was in the same range as between orobanchol and the three isomers (0.63).

Statistical analysis of the variation between rice cultivars

The correlations between explanatory variables (strigolactones) and response variables (infection parameters) were visualized in an RDA triplot. The high strigolactone producing rice cultivars IAC 165, IAC 1246, Gangweondo, Kinko and Dullo clustered together along the first ordinate on the right side of the plot, whereas low producers such as Kairyo, PI 160641, Koirao, Bhasmanik, Peh-Kuh, Shuang, Tattare, Agee, Anakila, TN 1 and Super Basmati clustered tightly together along the first ordinate on the left side of the plot. The remaining rice cultivars Binagimbing, Sonkanoir and 20 D located more or less in between these two clusters forming a group of moderate strigolactone producers. The strigolactones explained $79 \%$ of the variance in infection parameters and tillering $(\mathrm{MCP}, P$ value $<0.01)$ which is close to the explained variance by the first ordinate $(78.8 \%)$. There is a high correlation between the individual strigolactones as illustrated by the fact that their vectors point in almost the same direction along the first ordinate. Only the vector of orobanchol deviates slightly from the others. Due to this high correlation, each strigolactone explained a significant and sizeable fraction of the variance in infection parameters and tillering when only one strigolactone was added to the ordination model, with methoxy-5-deoxystrigol isomer 3 (Meth-3) explaining the highest $(76 \%, \mathrm{MCP}, P$ value $<0.01)$ and orobanchol explaining the lowest fraction of the variation $(61 \%, \mathrm{MCP}$, $P$ value $<0.01)$. However, forward selection showed that after addition of the most explanatory strigolactone (Meth3 ) to the ordination model, orobanchol is the most explanatory strigolactone for the rest of the variation $(2 \%$ MCP, $P$ value $=0.2$ ) (Suppl. Table S6). All the strigolactones correlated negatively with tillering and positively with $S$. hermonthica germination. The strigolactones also correlated positively, with attachment and emergence but less strong than with germination (Fig. 6) suggesting that there are other factors than the strigolactones influencing attachment and emergence of S. hermonthica after germination, as for example, in rice cultivar Dullo. Despite the similar total level of strigolactones exuded (and the similar germination), Dullo supported higher Striga emergence and attachment than Binagimbing (Fig. 6; Suppl. Tables S1-S2). Both have quite similar total amount of strigolactones but quite different composition (Fig. 5). Also among the other varieties there is strong variation in the strigolactone composition. This is visualized by the ratio's between the individual strigolactones (Suppl. Fig. 1; Suppl. Table 5). For example, PI160641 produces much more orobanchol than 2'-epi-5-deoxystrigol whereas for Gangweondo this is the reverse (Suppl. Fig. 1a), suggesting differential activity of the two branches of the strigolactone pathway in these cultivars. The low tillering rice cultivars IAC 165 and Gangweondo have much lower orobanchol to $2^{\prime}$-epi-5-deoxystrigol ratio both in the root exudate and in the root tissue compared with the high-tillering Agee and Super Basmati (Suppl. Table S5). Intriguingly, there is also variation for the ratio between strigolactone concentration in the exudate and in the root (Figs. 5, 6; Suppl. Table S5).
Fig. 6 Redundancy analysis plot visualizing the distance between rice cultivars (solid circles) based on a direct gradient analysis and showing patterns in the parasitism and tillering parameters (dotted arrows response variables) that could be explained by the strigolactones (solid arrows explanatory variables). The ordination axes are aggregates of the explanatory variables that best explain the response data

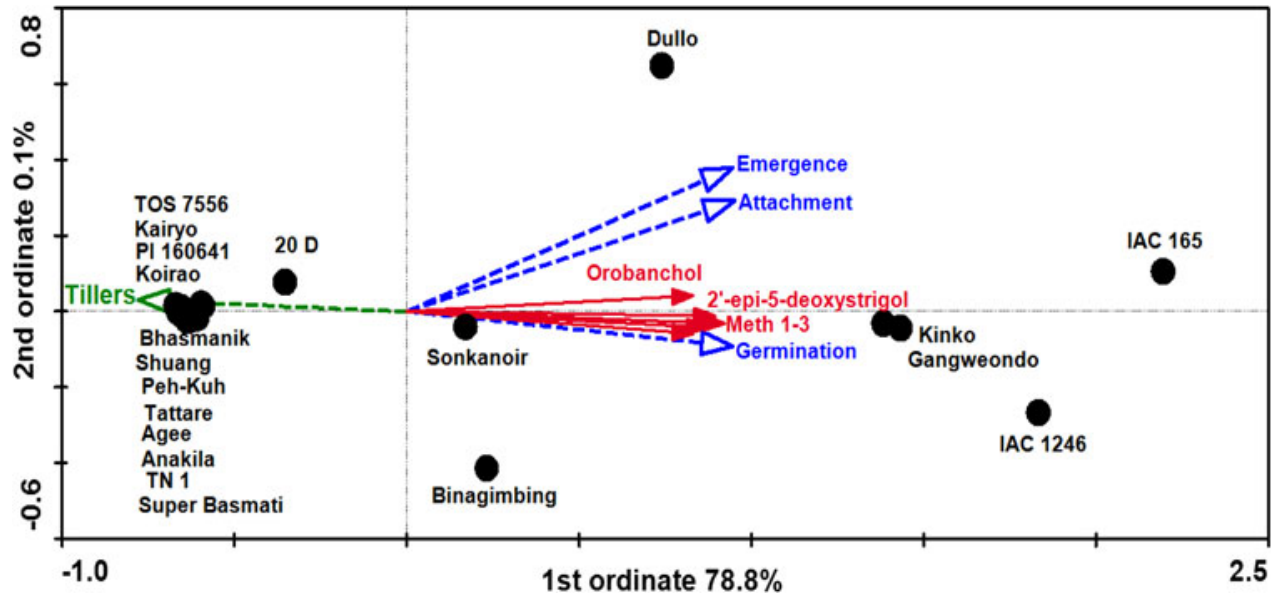


Agee, for example, has a high orobanchol/2'-epi-5-deoxystrigol ratio in the root, whereas in the exudate it is average. For TN1 it is more or less the opposite. Another interesting feature in the graphs is that there seems to be no consistent relation between orobanchol and the methoxyisomers (Suppl. Fig. 1b, c), and that in Bhasmanik the (putative) conversion of $2^{\prime}$-epi-5-deoxystrigol to both methoxy-isomers is highly active (Suppl. Fig. 1d, e).

\section{Discussion}

In the present study, the LC/MS quantification of strigolactones and the assessment of tillering and S. hermonthica infection in a range of rice cultivars collected from all over the world confirms the correlation between the regulation by strigolactones of above-ground plant architecture (tillering) and $S$. hermonthica infection as has been reported before (Gomez-Roldan et al. 2008; Umehara et al. 2008, 2010). We show that there is an extensive genetic variation for strigolactone production among the 20 rice varieties investigated and that this genetic variation is reflected in a strong variation in tillering and S. hermonthica infection. Low tillering, high strigolactone producing rice cultivars are more prone to $S$. hermonthica infection, and high-tillering, low strigolactone producing varieties are less prone to $S$. hermonthica infection. This shows that a genetic variation for strigolactone production exists in rice, opening up possibilities to introduce traits with low induction of $S$. hermonthica germination in rice. The results of the present study fit well with the postulated hypothesis that low secretion of strigolactones into the rhizosphere could be used to reduce $S$. hermonthica infection (Bouwmeester et al. 2003; Sun et al. 2008). In addition, our results with rice match with results on sorghum, showing that cultivars that produce low levels of the germination stimulants are resistant to S. hermonthica (Ejeta 2007; Mohamed et al. 2010). For rice, our study could imply that the introduction of more-tillering cultivars (with low strigolactone production) may prove to be an inexpensive approach to $S$. hermonthica management in rice, an increasing problem in parts of the African continent (Rodenburg et al. 2006, 2010; Rodenburg and Johnson 2009).

In addition to genetic variation in strigolactone amount, we also found a variation in the strigolactone composition. The strigolactones that we analysed, orobanchol, 2 -epi-5deoxystrigol and the methoxy-5-deoxystrigol isomers 1-3 (Fig. 1), can be divided into two groups based on their correlation to each other (Suppl. Table S5): orobanchol groups separately from the other four that exhibit a much higher correlation to each other. This is also visualized in Fig. 6 where the vector for orobanchol deviates from those of the other four strigolactones. The exact identity of the methoxy-5-deoxystrigol isomers has not yet been determined, but the higher correlation with $2^{\prime}$-epi-5-deoxystrigol could suggest that they have a $2^{\prime}$-epi-coupled D-ring which would make them methoxy-2'-epi-5-deoxystrigol isomers. Purification of high enough amounts of these isomers followed by NMR characterization should prove this assumption. The biosynthesis of orobanchol and the methoxy-2'-epi-5-deoxystrigol isomers would diverge from the step in which the D-ring is coupled/formed to produce 5-deoxystrigol-the precursor for orobancholand 2 -epi-5-deoxystrigol, the precursor for the methoxy$2^{\prime}$-epi-5-deoxystrigol isomers. Interestingly, we cannot detect 5-deoxystrigol (or only in minute amounts) suggesting that the conversion to orobanchol is very efficient and not rate-limiting. Nevertheless, there is substantial genetic variation in the rice varieties included in the present study in the ratio between orobanchol and $2^{\prime}$-epi5-deoxystrigol and the methoxy-5-deoxystrigol isomers (Suppl. Table S5; Suppl. Fig. S1). This large variation suggests that there is genetic variation in the stereochemistry of the D-ring coupling/formation. Similarly, the absence of a pattern in the orobanchol/methoxy-5-deoxystrigol isomer ratios is again suggestive that they might be methoxy-2'-epi-5-deoxystrigol isomers (Suppl. Table S5; Suppl. Fig. S1). Intriguing is the variation for the ratio between the strigolactone concentrations in the exudate and in the root (Fig. 5a, b; Suppl. Table S5). This difference in the ratio in root exudates and root tissues is suggestive of selectivity in the transport of strigolactones to the rhizosphere (to attract AM fungi) or to the shoot (for tillering inhibition). It has been demonstrated that different strigolactones exhibit different activities in the biological processes they control (branching inhibition, AM fungi hyphal branching and germination of parasitic plant seeds) (Kohlen et al. 2011b). Thus, differentiation in transport to the shoot or the rhizosphere could be biologically meaningful. Indeed, the presence of orobanchol in the xylem of Arabidopsis thaliana and tomato has recently been reported, whereas other strigolactones present in the root exudate were not detectable in the xylem (Kohlen et al. 2011a).

In the RDA analysis, strigolactones explained a considerable fraction of the variation in infection parameters and tillering (79\%). In the RDA plot, the strigolactones correlate strongly positively with germination, attachment and emergence of $S$. hermonthica and negatively with tillering of the rice cultivars. Germination significantly correlated positively with 2 -epi-5-deoxystrigol, orobanchol and methoxy-5-deoxystrigol isomer-3 (Suppl. Table S6). In in vitro germination bioassays with standards of orobanchol and 2'-epi-5-deoxystrigol, germination of $S$. hermonthica was induced more efficiently by $2^{\prime}$-epi-5deoxystrigol than by orobanchol (data not shown). Germination bioassays with fractions of rice root exudate 
suggest that the methoxy-5-deoxystrigol isomers are also highly effective in inducing germination of $S$. hermonthica (C Cardoso, WUR, personal communication). The regression analysis in the present study further confirms this tendency. Methoxy-5-deoxystrigol isomer 3 contributed most to the explanation of the variation in $S$. hermonthica germination followed by $2^{\prime}$-epi-5-deoxystrigol while orobanchol did not contribute (Suppl. Table S4). The correlation of attachment and emergence with the amount of strigolactones is lower than for germination but still considerable. Clearly, not all germinated $S$. hermonthica seeds will also emerge. The induction of $S$. hermonthica seed germination by the strigolactones is just the first step in the parasitation process. Subsequently, successful attachment and a compatible interaction are requirements for emergence. The difference in the direction of emergence and germination arrows with attachment points to differences in resistance between the rice varieties in these later stages of the parasitation process (Fig. 6). Differences in resistance in the germination phase as well as in post-attachment resistance were recently also reported for the New Rice for Africa NERICA's (Cissoko et al. 2011; Jamil et al. 2011b).

AM-fungal symbiosis in high-tillering rice cultivars might be affected negatively by the lower production of strigolactones which could cause reduced hyphal branching in the root zone (Garcia-Garrido et al. 2009). However, the strigolactone composition of the exudate may be a crucial factor here as it has been shown that there is a large difference in the capacity of individual strigolactones to induce hyphal branching in AM fungi (Akiyama et al. 2010). Rice varieties producing the right mix of strigolactones could have the desired tillering and AM-fungal phenotype while at the same time not inducing too much $S$. hermonthica germination. Since there is genetic variation for the strigolactone composition in rice, selection could potentially alter the strigolactone composition to a more desired mixture.

In conclusion, the tillering potential of rice turns out to be an important marker for the plant's susceptibility to $S$. hermonthica infection. This phenomenon could be helpful in making decisions about the extent of $S$. hermonthica infection to be expected in germplasm collections and could hence guide breeders in selecting the right materials when breeding for Striga resistance. Selection of suitable, high-tillering cultivars (which we have now shown to produce less strigolactones) might be a useful strategy to reduce serious cereal losses by these noxious parasitic weeds.

Acknowledgments Funding from Higher Education Commission (HEC to MJ) Pakistan and the Netherlands Organization for Scientific Research (to HJB VICI grant 865.06.002 and Equipment Grant
834.08.001 and to BH: ERGO Grant 838.06.012) is acknowledged. This project is (co) financed by the Centre for Bio Systems Genomics (CBSG) which is part of the Netherlands Genomics Initiative/Netherlands Organization for Scientific Research. We thank Ms. Flora De Guzman (International Rice Research Institute, Philippines), Dr. Julie Scholes (University of Sheffield, United Kingdom) and Dr. Abdul Rehman (National Agricultural Research Center, Pakistan) for providing seeds of various rice cultivars. We are also grateful to Cheickna Diarra and A. G. Babiker for providing S. hermonthica seeds and to Binne Zwanenburg (Radboud University, Nijmegen, the Netherlands), Koichi Yoneyama (Weed Science Center, Utsunomiya University, Japan) and Kohki Akiyama (Osaka Prefecture University, Japan) for kind provision of GR24, and standards of orobanchol, $2^{\prime}$ epi-orobanchol, 5-deoxystrigol and 2'-epi-5-deoxystrigol and Tadao Asami for providing $\mathrm{D}_{6}-2^{\prime}$-epi-5-deoxystrigol. Kind help in statistical analysis by Tahira Jamil, (Wageningen University, the Netherlands) is also acknowledged.

Open Access This article is distributed under the terms of the Creative Commons Attribution Noncommercial License which permits any noncommercial use, distribution, and reproduction in any medium, provided the original author(s) and source are credited.

\section{References}

Akiyama K, Hayashi H (2006) Strigolactones: chemical signals for fungal symbionts and parasitic weeds in plant roots. Ann Bot 97:925-931

Akiyama K, Matsuzaki K, Hayashi H (2005) Plant sesquiterpenes induce hyphal branching in arbuscular mycorrhizal fungi. Nature 435:824-827

Akiyama K, Ogasawara S, Ito S, Hayashi H (2010) Structural requirements of strigolactones for hyphal branching in $\mathrm{AM}$ fungi. Plant Cell Physiol 51:1104-1117

Bouwmeester HJ, Matusova R, Sun ZK, Beale MH (2003) Secondary metabolite signalling in host parasitic plant interactions. Curr Opin Plant Biol 6:358-364

Bouwmeester HJ, Roux C, Lopez-Raez JA, Becard G (2007) Rhizosphere communication of plants, parasitic plants and AM fungi. Trends Plant Sci 12:224-230

Cissoko M, Boisnard A, Rodenburg J, Press MC, Scholes DJ (2011) New Rice for Africa (NERICA) cultivars exhibit different levels of post-attachment resistance against the parasitic weeds Striga hermonthica and Striga asiatica. New Phytol. doi:10.1111/ j.1469-8137.2011.03846.x

Crawford S, Shinohara N, Sieberer T, Williamson L, George G, Hepworth J, Muller D, Domagalska MA, Leyser O (2010) Strigolactones enhance competition between shoot branches by dampening auxin transport. Development 137:2905-2913

Ejeta G (2007) Breeding for Striga resistance in sorghum: exploitation of an intricate host-parasite biology. Crop Sci 47:S216S227

Estabrook EM, Yoder JI (1998) Plant-plant communications: rhizosphere signaling between parasitic angiosperms and their hosts. Plant Physiol 116:1-7

Garba A, Fagam AS, Fushison GG (2007) Contribution of environmental factors to tillering and yield of rice during dry season in Bauchi, Nigeria. Int J Trop Agric Food Syst 1:42-47

Garcia-Garrido JM, Lendzemo V, Castellanos-Morales V, Steinkellner S, Vierheilig H (2009) Strigolactones, signals for parasitic plants and arbuscular mycorrhizal fungi. Mycorrhiza 19:449-459 
Gomez-Roldan V, Fermas S, Brewer PB, Puech-Pages V, Dun EA, Pillot JP, Letisse F, Matusova R, Danoun S, Portais JC, Bouwmeester $\mathrm{H}$, Becard $\mathrm{G}$, Beveridge CA, Rameau C, Rochange SF (2008) Strigolactone inhibition of shoot branching. Nature 455:189-194

Harrison JM (2005) Signaling in the arbuscular mycorrhizal symbiosis. Annu Rev Microbiol 59:19-42

Hayward A, Stirnberg P, Beveridge C, Leyser O (2009) Interactions between auxin and strigolactone in shoot branching control. Plant Physiol 151:400-412

Jamil M, Charnikhova T, Cardoso C, Jamil T, Verstappen F, Bouwmeester H (2011a) Quantification of the relationship between strigolactones and Striga hermonthica in rice under varying levels of nitrogen and phosphorus. Weed Res 51:373-385

Jamil M, Rodenburg J, Charnikhova T, Bouwmeester H (2011b) Preattachment Striga hermonthica resistance of New Rice for Africa (NERICA) cultivars based on low strigolactone production. New Phytol. doi:10.1111/j.1469-8137.2011.03850.x

Kapulnik Y, Delaux PM, Resnick N, Mayzlish-Gati E, Wininger S, Bhattacharya C, Sejalon-Delmas N, Combier JP, Becard G, Belausov E, Beeckman T, Dor E, Hershenhorn J, Koltai H (2011) Strigolactones affect lateral root formation and root-hair elongation in Arabidopsis. Planta 233:209-216

Kim HK, Luquet D, van Oosterom E, Dingkuhn M, Hammer G (2010a) Regulation of tillering in sorghum: genotypic effects. Ann Bot 106:69-78

Kim HK, van Oosterom E, Dingkuhn M, Luquet D, Hammer G (2010b) Regulation of tillering in sorghum: environmental effects. Ann Bot 106:57-67

Kohlen W, Charnikhova T, Liu Q, Bours R, Domagalska MA, Beguerie S, Verstappen F, Leyser O, Bouwmeester H, RuyterSpira C (2011a) Strigolactones are transported through the xylem and play a key role in shoot architectural response to phosphate deficiency in non arbuscular mycorrhizal host Arabidopsis. Plant Physiol 155:974-987

Kohlen W, Ruyter-Spira C, Bouwmeester H (2011b) Strigolactones: a new musician in the orchestra of plant hormones. Botany (in press)

Koltai H, Dor E, Hershenhorn J, Joel DM, Weininger S, Lekalla S, Shealtiel H, Bhattacharya C, Eliahu E, Resnick N, Barg R, Kapulnik Y (2010) Strigolactones effect on root growth and root hair elongation may be mediated by auxin efflux carriers. J Plant Growth Regul 29:129-136

Leyser O (2003) Regulation of shoot branching by auxin. Trends Plant Sci 8:541-545

Lynn DG, Chang M (1990) Phenolic signals in cohabitationimplications for plant development. Annu Rev Plant Physiol Plant Mol Biol 41:497-526

Matusova R, Rani K, Verstappen FWA, Franssen MCR, Beale MH, Bouwmeester HJ (2005) The strigolactone germination stimulants of the plant parasitic Striga and Orobanche spp. are derived from the carotenoid pathway. Plant Physiol 139:920-934

Mohamed AH, Housley TL, Ejeta G (2010) An in vitro technique for studying specific Striga resistance mechanisms in sorghum. Afr J Agric Res 5:1868-1875

Ongaro V, Leyser O (2007) Shoot branching in Arabidopsis. Comp Biochem Physiol A-Mol Integr Physiol 146:S237-S238

Rodenburg J, Johnson DE (2009) Weed management in rice based cropping systems in Africa. Adv Agron 103:149-218

Rodenburg J, Bastiaans L, Kropff MJ (2006) Characterization of host tolerance to Striga hermonthica. Euphytica 147:353-365

Rodenburg J, Riches CR, Kayeke JM (2010) Addressing current and future problems of parasitic weeds in rice. Crop Prot 29:210-221

Ruyter-Spira C, Kohlen W, Charnikhova T, van Zeijl A, van Bezouwen L, de Ruijter N, Cardoso C, Lopez-Raez JA, Matusova R, Bours R, Verstappen F, Bouwmeester HJ (2011) Physiological effects of the synthetic strigolactone analog GR24 on root system architecture in Arabidopsis: another belowground role for strigolactones? Plant Physiol 155:721-734

Sun Z, Hans J, Walter MH, Matusova R, Beekwilder J, Verstappen FWA, Ming Z, van Echtelt E, Strack D, Bisseling T, Bouwmeester HJ (2008) Cloning and characterisation of a maize carotenoid cleavage dioxygenase (ZmCCD1) and its involvement in the biosynthesis of apocarotenoids with various roles in mutualistic and parasitic interactions. Planta 228:789-801

ter Braak CJF (1988) Canoco-an extension of decorana to analyze species environment relationships. Vegetatio 75:159-160

Umehara M, Hanada A, Yoshida S, Akiyama K, Arite T, TakedaKamiya N, Magome H, Kamiya Y, Shirasu K, Yoneyama K, Kyozuka J, Yamaguchi S (2008) Inhibition of shoot branching by new terpenoid plant hormones. Nature 455:195-200

Umehara M, Hanada A, Magome H, Takeda-Kamiya N, Yamaguchi S (2010) Contribution of strigolactones to the inhibition of tiller bud outgrowth under phosphate deficiency in rice. Plant Cell Physiol 51:1118-1126

Ward SP, Leyser O (2004) Shoot branching. Curr Opin Plant Biol 7:73-78

Wu GW, Wilson LT, McClung AM (1998) Contribution of rice tillers to dry matter accumulation and yield. Agron J 90:317-323

Xie X, Yoneyama K, Yoneyama K (2010) The strigolactone story. Annu Rev Phytopathol 48:93-117

Yoder JI (2001) Host-plant recognition by parasitic Scrophulariaceae. Curr Opin Plant Biol 4:359-365

Yoneyama K, Yoneyama K, Takeuchi Y, Sekimoto H (2007) Phosphorus deficiency in red clover promotes exudation of orobanchol, the signal for mycorrhizal symbionts and germination stimulant for root parasites. Planta 225:1031-1038

Yoneyama K, Awad AA, Xie XN, Takeuchi Y (2010) Strigolactones as germination stimulants for root parasitic plants. Plant Cell Physiol 51:1095-1103 